Original Article

\title{
Optional Vaccines for Better Immunization : Awareness among M others
}

\author{
Punarva M.H. \\ Assistant Professor, Department of Pediatric Nursing, Alva's College of Nursing, \\ Menezes Complex, M oodbidri \\ Correspondence \\ Punarva M.H. \\ Assistant Professor, Department of Pediatric Nursing, Alva's College of Nursing, M enezes Complex \\ Moodbidri - 574 227, Karnataka, India. \\ Mobile : +91 9341771187 E-mail : punarva.h@gmail.com
}

\begin{abstract}
Effectiveness of structured teaching programme on knowledge of optional vaccines among mothers of under five children in selected rural areas. The Sample include 30 mothers of under five children. Research approach was quantitative - evaluative approach anddesign used was quasi experimental pretestposttest design.In the first phase, researcher assessed pretest knowledge and health teaching was given to selected mothers with the duration of 45 minutes. The posttest knowledge was assessed over a period of 7 days after the intervention. The community participation has found to be effective with a Paired $t$ valve $(P \varangle .001)$ shows significance which indicates community participation was effective in terms of knowledge pain.
\end{abstract}

Keywords: optional vaccines, knowledge

\section{Introduction}

W H O estimates that in 2007 the under five mortality was 78.8 deaths / 1000 live births. In that, most of the deaths are attributed to vaccine preventable diseases like tuberculosis, typhoid; pneumonia, polio, diarrheal diseases, and tetanus etc.Many of the mothers are unaware about the number of doses of each vaccine and also about the time limit for the particular vaccine that should be administered to the child.

Immunization describes the whole process of delivery of a vaccine and the immunity it generates in an individual and population. A vaccine is a special form of a disease-causing agent (e.g., virus or bacteria) that has been developed to protect against that disease. Immunization forms one of the most important and cost effective strategies for the prevention of childhood Access this article online Quick Response Code

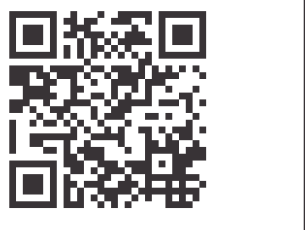
sicknesses and disabilities and is thus a basic need for all children. The last 20 years have seen an explosion in the number of new vaccines. Many other vaccines are available against many other diseases like typhoid fever, chicken pox pneumonia, meningitis etc.

National Immunization services now offers protection against an additional diseases in some specific areas. Hepatitis $B$ Vaccine protects against serious disease of the liver. Homophiles influenza type b or Human Influenza B Vaccines (HIB) is another vaccine which protects against pneumonia, meningitis. Regarding Meningitis 2005 about 8357 cases were reported in India with 485 death. WHO (2007) each year in the world about 145 million children are born around 2.4 million deaths among children under five are still due to vaccine preventable diseases and infections in early life.Mortality rate may be greater in developing countries, because of low resistance of these children against infection. In the developing world some $23 \%$ of deaths among children under five years occur in the first month. However about 3 million babies in the developing countries die during early childhood. In recent years however relatively low immunization levels in this age group have occasional scattered out break of certain disease. For this reason in spite of the national effort some immunizations are administered optionally to improve the immunization levels of all children. This vaccination helps 
to making the babies' immune system stronger.

Immunization is the most effective tool which greatly prevent and reduce incidence and severity of common seven diseases include of whooping cough, diphtheria, tetanus, hepatitis, tuberculosis, poliomyelitis, measles, which a together responsible as leading cause of all death in children under the age five. During the survey the researcher had the opportunity to interact with the parents It was found that the parents of the under five children were unaware of giving vaccines and its importance in the health of their child. In the light of the above facts, it is an essential fact that mothers of under five should bring up their knowledge about the optional vaccines in order to bring up a new generation with less risk. Hence the investigator was interested to assess the knowledge of mothers regarding optional vaccines.

\section{Materials and Methods:}

\section{Study Hypothesis}

$\mathrm{H} 1$ : Knowledge level of mothers will not be increased after structured teaching programme on optional vaccines.

$\mathrm{H} 2$ : There will be no significant association between knowledge score of mothers regarding optional vaccines and selected demographic variables.

\section{Study design and Study population}

This quantitative study adopted an evaluative approach to identify the effectiveness of structured teaching programme on knowledge regarding optional vaccines and the design used was quasi experimental pretest-post test group design. The study population was mothers of under five children who resides in (Dharagudele and Makki) Moodbidri

The sample size was 30 mothers of under five children. Administrative permissions was obtained from concerned authorities. The mothers were informed of the purpose of the study and the content was taken from them. Confidentiality was maintained during data collection. Ethical clearance was obtained from the institutional ethics committee, Alva's hospital, M oodbidri

\section{Data collection instrumentsand measurements}

The following tools were used to collect the data

\section{Tool 1: Background Performa}

It consists ten items for obtaining information's regarding Age, Type of family, Educational status, occupation, religion, Source of information, Family income Distance from immunization center.The tool was validated by eight experts, pretested among five mothers residing in a village.

\section{Tool 2 : Structured knowledge questionnaire on knowledge on optional vaccines}

The questionnaire dealt with Introduction about immunization, types of vaccine, National immunization schedule and optional vaccines. It had a total of 28 items divided into two sections, section $A$ and $B$ with 8 and 20 items in each section respectively. The items in the section A had 4-5 alternate responses and the items in the section $B$ had 4 responses. The respondents were requested to select the best possible option by encircling the correct answer. The minimum score was 1 and maximum score was 20. Knowledge score was arbitrarily classified as inadequate Inadequate Knowledge (0 - 10), Moderately Knowledge (11-15) Adequate Knowledge (16-20). The tool was validated by eight experts, translated in Kannada and pretested among five mothers residing in a village.

Pilot study was conducted among 10 sample and changes were made in the tool accordingly.

\section{Procedure}

The study was carried out. Tool 1 and 2 was administered among the selected participants. Firstly pretest was conducted, the health teaching by the researcher was given to selected mothers. The post- test knowledge was assessed over a period of 7-9 days after the intervention.

\section{Statistical analysis}

The data were analyzed using both Descriptive and inferential using Statistical package for Social Science version 16 (SPSS 16).

Descriptive statistics: Frequency and percentage distribution, mean and standard deviation were used to 
describe the sample characteristics.

Inferential statistics: $M$ ann Whitney $U$ test and paired t test was used to test the effectiveness of intervention between and within the group respectively.

\section{Results}

In 30 samples $11(36.6 \%)$ mothers belongs to age group of 31 and above, 9(30\%) mothers belongs to age group of 27 $30,5(16.66 \%)$ mothers belongs to age group of $19-22$ and 23-26. (Type of family) $15(50 \%)$ belongs to nuclear family, $15(50 \%)$ mothers belongs to joint family. (Education) $12(40 \%)$ have primary education, 9(30\%) have secondary education and 9(30\%) have higher secondary. 13(43.3\%) are very near to the immunization center, $13(43.3 \%)$ reach in half an hour, 4(13.3\%) reach in one hour. (occupational status) $15(50 \%)$ mothers are house wife, $11(36.6 \%)$ mothers are coolie, $3(10 \%)$ mothers are self-employed, $1(3.3 \%)$ mothers is private employee.( source of information) $15(50 \%)$ mothers are health personals, $8(26.6 \%)$ have no information, $3(10 \%)$ mothers got information from electronic media ,2(6.6\%) mothers interacted with friends/neighbors, 2(6.6\%) mothers got information from relatives/family members. religion $17(56.6 \%)$ of the mother are Hindu, $11(36.6 \%)$ of the mother are M uslims, 2(6.6\%) of the mothers are Christians. 10(33.3\%) have family income 2001-4000 per month, $9(30 \%)$ have income less than or equal to $2000,8(26.6 \%)$ have $4001-6000,3(10 \%)$ have 6000 and above.

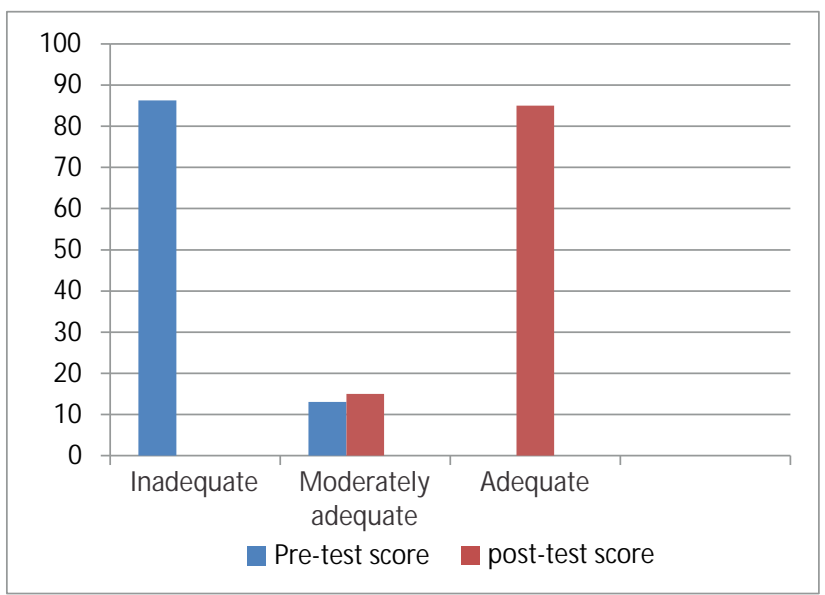

Fig. 1 : Bar diagram showing the pre-test and post-test knowledge Score of M others
Table 1 : Comparison of area wise pretest and post-test knowledge scores

\begin{tabular}{|l|c|c|c|c|c|c|}
\hline \multirow{2}{*}{$\begin{array}{l}\text { area wise } \\
\text { analysis }\end{array}$} & \multicolumn{3}{|c|}{ Pre- test } & \multicolumn{3}{c|}{ Post-test } \\
\cline { 2 - 7 } & Mean & Mean \% & SD & Mean & Mean \% & SD \\
\hline $\begin{array}{l}\text { Knowledge of } \\
\text { Immunization }\end{array}$ & 1.20 & 30 & 0.88 & 3.36 & 84 & 0.49 \\
\hline $\begin{array}{l}\text { Routine } \\
\text { Immunization }\end{array}$ & 1.26 & 25.2 & 0.94 & 3.96 & 79.2 & 0.85 \\
\hline $\begin{array}{l}\text { Optiona } \\
\text { vaccines }\end{array}$ & 4.0 & 36.3 & 2.39 & 9.4 & 85.4 & 1.22 \\
\hline $\begin{array}{l}\text { Combined } \\
\text { score }\end{array}$ & 6.46 & 32.3 & 3.12 & 16.73 & 83.6 & 1.79 \\
\hline
\end{tabular}

The study reveals that there is significant association between pre-test knowledge score and demographic variable like child's Type of family (Chi-square $=7.846$, $\mathrm{df}$ $1, p=0.005)$,but there was no significant association between the pre-test knowledge and any other demographic variables like income of family, source of information and distance between home and immunization center..

\section{Effectiveness of structured teaching programme in terms of gain knowledge}

In the study the mean post-test knowledge score (16.73) was higher than pre-test knowledge scores (6.46). The mean difference between pre-test and post-test score (10.27) of knowledge is significant at 0.001 level, as't' = $15.87(\mathrm{P} \varangle 0.001)$.

Hence the research hypothesis $\mathrm{H} 1$ was accepted. The difference of means observed is a true difference. Hence it can be concluded that Structured Teaching Programme has an influence in improving the knowledge of mothers on Optional vaccines.

\section{Discussion}

In the present study knowledge of mother was assessed regarding optional vaccines, during the pre-test knowledge scores of mothers on optional vaccines 25(83.3) percent) mothers had Inadequate knowledge and 4(13.3 percent) had moderately adequate knowledge and 1(3.3\%) had Adequate knowledge. During the post-test knowledge scores of mothers on optional vaccines 14(46.6 percent) mothers had adequate knowledge and 16(53.3 percent) had moderately adequate knowledge.For the success of 
any programme, it is important to create public awareness and have wholehearted participation of the people and healthcare personal. In spite of many educational programs targeting the vulnerable group of population, mother and child the health scenario of our country is far below from satisfactory. 9.7 million children are dying worldwide before five years of age which include $21 \%$ from India. Of this $19 \%$ isdue to pneumonia, $17 \%$ is due to diarrhea, malaria $8 \%$.and measles $4 \%$.In India 9.4 million children are not immunized.

\section{Conclusion}

This study findings revealed that structured teaching programme was successful in improving the knowledge of mothers so that they can practice optional vaccinations of their children in time which will be helpful in reducing the incidence of childhood mortality and morbidity rate.

\section{References}

1. UNICEF-Immunization.introduction.6 December 2007http:// www.unicef.org/immunization/index. html.

2. Facts and statistics about the Infant mortality rate of India.2009. Ihtml

3. Nighat Nisar, Muddasir Mirza, Majid Hafeez Qadri. Knowledge, attitude and practices of mothers regarding immunization ofone year old child at M awatch Goth, Kemari town, Karachi. January - M arch 2010.URL:

4. India to offer a new effective typhoid vaccine soon. Wednesday, August 09, 2006. URL: http://biospectrumindia.ciol.com/content /news/20608091.asp.

5. India to offer a new effective typhoid vaccine soon. Wednesday, August 09, 2006. URL : http://biospectrumindia.ciol.com/content /news/ 20608091.asp.

6. Rachna Kapoor, Sheetal Vyas. Awareness and knowledge of mothers of under five children regarding immunization in Ahmedabad. December 2010. URL: http://iapsmgc.org/oa2.pdf

7. Progress for Children Report - A Statistical Review December 2007. http:// www.unicef.org/ india / resources_3766.htm

8. Causes of Child Death http://www.globalhealth.org/ child_health/ child_mortality/ causes_death/.

\section{Implications}

The nursing curriculum should consist of knowledge related to vaccine preventable diseases, immunization schedule and information regarding optional vaccines using different methods of teaching. Nursing students should be taught to consider health education as a way of life and practice it in their day to day activities. The nurse administrator should create awareness among mothers in order to prevent diseases and to improve their knowledge on delayed and optional vaccines by posters, charts etc. This study helps the nurse researcher to develop insight into the new and current teaching modules and materials for educating the mothers on optional vaccines. Studies can be done including knowledge, attitude and practice on immunization among mothers. 